\title{
Using Educational Management Systems to Enhance Teaching and Learning in the Classroom
}

An investigative case study

\author{
Christopher Tatnall and Arthur Tatnall

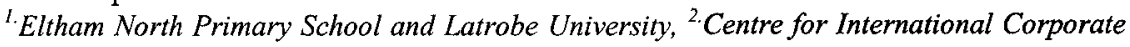 \\ Governance Research, Victoria University, Australia
}

\begin{abstract}
All schools store a considerable amount of administrative data on their students, and this is collected from a number of different sources. Depending on the requirements of their national or state education systems most schools store this data in a prescribed format so that it can be used to prepare reports for these education authorities and for local school use. The question we ask is whether any other classroom use can be made of all this data, and that is the question addressed in this paper. In the paper we examine a case study of a primary school in the state of Victoria, Australia and how it is attempting to come to grips with this question.
\end{abstract}

Keywords: Educational Management Systems, tracking and monitoring of student learning, enhancement of teaching and learning, integrated databases.

\section{INTRODUCTION}

Every school needs to store a large amount of administrative data relating to individual students and student cohorts. This data is collected from many formal and informal sources including: Student Enrolments, Early Years Interviews, Observational Surveys, Running Records, other Formal Testing and Anecdotal Notes. In Government schools in Victoria (Australia) the principal computer system used for this purpose is known as CASES-21, the use of which is mandated by the Department of Education for school administrative purposes. Many schools also keep other student data either on paper or in other unlinked systems. This research project was the result of a period of 'Teacher Professional Leave' (by Christopher Tatnall) and involved an investigation of whether:

1. Existing electronic data could also be used in some way to enhance teaching and learning in the primary school classroom.

Please use the following format when citing this chapter:

Tatnall, C. and Tatnall, A., 2007, in IFIP International Federation for Information Processing, Volume 230, Knowledge Management for Educational Innovation, eds. Tatnall, A., Okamoto, T., Visscher, A., (Boston: Springer), pp. 75-82. 
2. Other student data stored by schools could be linked to the data already stored in electronic format in CASES-21 in order to facilitate things such as assessment and reporting. This type of data is primarily used for monitoring and accountability at the school level and could, potentially, be useful to classroom teachers to identify individual student needs and to improve student outcomes.

This paper reports on an investigative study of how several Victorian schools make use of their educational management systems. Data was collected from the following medium to large primary schools in the Northern and Eastern suburbs of Melbourne: Eltham North, Apollo Parkways, Glen Katherine, Milgate and Doncaster Gardens, as well as Scotch College, a large independent school in Hawthorn, and the South Eastern Region Computer Training Centre (SERCT) of the Victorian Department of Education. Another goal of the project was to develop an integrated database that could be used by classroom teachers to track and monitor student learning at any point in time during the children's attendance at Eltham North Primary School.

\section{ADMINISTRATIVE SYSTEMS IN VICTORIAN SCHOOLS}

CASES-21 (Computerised Administrative System Environment in Schools) is used in Victorian Government Schools to support their needs for administrative and financial management. An earlier version of CASES has been in use since the late 1980s (Tatnall 1995). It was developed as a tool for overall school administration and as a means of reporting back from schools to the Department of Education. No consideration was given to its use in school classrooms either to support teacher administrative functions or to enhance teaching and learning (Tatnall 1995; Tatnall and Davey 2001; Davey and Tatnall 2003).

CASES-21 aims to provide school administrative support staff with secure access to data entry and reporting modules that supports school administration and finance functions. The Department of Education claims that it has been designed to be modified to meet evolving school business needs. It currently has two main modules (Department of Education 2005):

- An Administration Module to provide student administration support, including the facility to manage: student and family data; student pastoral data; student medical information; student attendance; student achievement; student discipline/welfare; accident and incident data; activities (including student excursions); school management information; basic timetabling; daily organisation; and school associations (e.g. Parents Club and School Council). Almost all Government schools are now using this module. 
- A Finance and Local Payroll module that aims to assist schools to: create and receipt family and student invoices; manage family debtors, sundry debtors and creditors; manage the school's asset register; process and manage the school's local payroll; manage school finances and budgets; generate appropriate financial reports. Currently only a small number of schools are running CASES-21 Finance whilst the remainder use the older version in CASES.

The Department of Education has eleven CASES Training Centres located throughout Victoria to provide professional development and training in the use of CASES and related administrative applications. Those attending this training are predominantly School Support Officers (administrative support staff) and School Principals. The School Support Officers attend to learn how to use the CASES system, while the Principals attend in order to gain an understanding of how CASES can be used to support the management of their school. Very few classroom teachers attend the training sessions as CASES typically has not been used by the classroom teacher. There is also a training course on 'Seemless Views' to show how CASES-21 data can be linked to Microsoft Access and FileMaker databases, as well as other applications such as Microsoft Word and Excel.

The prime purpose of CASES-21 is to enable reporting from schools back to the Department of Education. For security reasons each Government School in Victoria has two distinct (unconnected) computer networks: an administrative office network running CASES-21, and a curriculum network for use by classroom teachers. The curriculum network is wireless enabled but not the administrative network. As CASES-21 runs only on the administrative network a classroom teacher wanting to access CASES-21 data must use a computer in the school administrative office that is connected to this network.

Other school administrative systems provided by the Department of Education include building maintenance and teacher employment, but these are not relevant to this paper. A multitude of other administrative computer systems, both commercial and locally written, are also use in schools. These include:

- Systems used for reporting student information to parents

- Commercial school reporting packages used in a large number of schools.

- Some schools write up student reports as Microsoft Word documents without using any additional software.

- A few schools use software that has been custom-built for them

- Other schools still send handwritten reports home to parents.

- Systems for handling student achievement data

- CASES-21 has facilities for handling data of this type, but as the purpose of this system is to transmit this data back to the Department of Education there are no additional facilities for reporting to parents. 
- All schools are required to enter data into CASES-21, but teachers do not have access to the program, and administrative office staff usually perform this operation. Data is typically kept in different ways by each teacher in each school.

- Commercial packages are not used very much at present, but some of these that prepare reports to parents also have some basic ways of storing achievement data.

- Use is made of database management packages such as Microsoft Access and FileMaker in some schools.

- CASES-21 allows data to be typed in, but at the moment there seems to be no easy way of importing data from other databases or software applications.

- Systems for tracking various data related to students, such as:

- Achievement.

- Special programs.

- Visits from visiting professionals such as speech pathologists, psychologists, eye specialists etc.

- Additional homework etc for high / low achievers, individual learning plans.

These systems must work across year levels and keep track of each student's progress for the entire period he or she is at the school. They should also be accessible to all teachers (CASES-21 is not). One problem is that schools have different processes for storing and tracking this data. In some case this is handwritten, it may be in folders in filing cabinets, it may be in simple unconnected databases or spreadsheets, or it could reside in basic commercial packages.

CASES-21 allows the export of data to other systems, but it does not allow data to be imported from these other systems. This means that if the same data is required for use in several different applications, unless it is entered first into CASES-21 and then exported to the other system, it must be retyped for use in CASES-21.

\section{ELTHAM NORTH PRIMARY SCHOOL: VISION, CORE VALUES AND PHILOSOPHY}

"Eltham North Primary School is a community united by a commitment to learning. It was founded in 1924 and is intensely proud of its educational achievement in serving the community of Eltham. We are located one kilometre north of the township of Eltham Central, a residential suburb renowned for its peaceful bush surroundings. At the commencement of 2003, the school population of 425 students included $46 \%$ girls and $54 \%$ boys. Of the current student body, $98 \%$ are Australian born and $2 \%$ of our students do not use English language as their first language at home." (Eltham North Primary School 2003). 
In the School's Charter, the vision statement speaks about empowering students to help them develop communication skills and relationships that recognise and explore the "increasing responsibility they have for their own learning". It states that the school will provide an innovative and progressive learning environment that "engages, challenges and extends the learning capacity of all students". The core values of the school's learning community articulated in the Vision Statement involve building up strong foundations upon which the students can achieve, and support themselves and the well-being of others. It points out that these values are embodied in the school motto "Growing, Discovering, Creating Together" (Eltham North Primary School 2003).

Eltham North Primary School's Charter goes on to indicate that the school's teaching philosophy is based on a commitment to prepare students with the attributes and competencies needed to turn them into "active and responsible citizens in an ever-changing global society". It indicates that the school aims to encourage and provide "a caring atmosphere where the children feel emotionally, socially and physically secure", and makes use of reflective learning and problem solving so that negotiation and skill development can be used to create a process for insightful curriculum development (Eltham North Primary School 2003).

\subsection{Eltham North's Student Information System}

Eltham North Primary School's current system for handling student data and keeping copies of reports to parents etc. involves storing this data in a filing cabinet. Each classroom teacher keeps summaries of their student data in a large $\mathrm{A} 3$ folder with a file in a filing cabinet for each student. At the end of each year all of this data is collected by support staff and collated, ready for redistribution to this grade's next year teacher. This is a lengthy operation, and as part of this project we developed a Student Information System, which collected and stored a lot of this data electronically.

The school recently committed significant resources to the development of this new system, which has functions such as:

- Giving classroom teachers access to the name, phone number and emergency contact details (downloaded from CASES-21) for their students, without the need for them to go to the school office system.

- Providing a history of each child's schooling: grades, years, teachers (no achievement data as yet - this is to be added in the future) and involvement in special programs.

- Track (keep a record of) each child's individual learning plans.

- Link Microsoft Word reports to a database entry for each child.

As the school makes use of Apple Macintosh computers, the database was written using FileMaker Pro 8, and is stored on a central server on the curriculum network. (The reader will remember that the school has two 
different unconnected networks and so data on one cannot be accessed from the other). Each teacher in the school has access to the database via their own laptop using the school's wireless network. The database is password protected with different teachers have different access levels.

Teachers at the school have readily embraced the new system which has cut down their administrative workload and made relevant student information readily available to them. Eltham North Primary School is committed to extending the use of the database by purchasing more FileMaker licences and providing time and resources to make further additions to the database system.

\section{ADMINISTRATIVE SYSTEMS IN OTHER VICTORIAN SCHOOLS}

The study also investigated administrative databases used in other schools. As there is no single program or package recommended by the Department of Education many schools have created their own databases or purchased commercial packages. Part of this research included involvement in a working party based at Glen Catherine Primary School. The working party included teachers and administrators from six different schools in the North Eastern Suburbs of Melbourne. One of the objectives of this group was to find a package to both assist with the writing of student reports and also to store data on students. A plethora of programs have been written and available for schools to purchase that make report writing easier for the classroom teacher, however we found that there were no suitable packages for tracking and storing data on individual students.

Several schools have created their own systems. We viewed a number of these but did not find one that would be suitable for Eltham North Primary School. Many schools have used FileMaker Pro to create very simple databases, but none of those seen were fully relational. One school had lots of different databases which were not linked, meaning that teachers had to write the same information into several different databases. They were also not linked to the school's administrative system (CASES-21). Several schools used Microsoft Access but this has limited application in primary schools as many use Apple Macintosh Computers. FileMaker Pro was seen as a good compromise as it can be used on both platforms.

The working party at Glen Catherine, after viewing many different school databases and commercial packages, decided to recommend a commercial package for their schools that is used primarily to assist classroom teachers to write student reports to send home to parents. They found that there were no commercial packages readily available to track student's performance and academic achievement over time.

We also visited the Austin Hospital School, a Government school that services this hospital and also has outreach programs in other Government Schools. This school had a database created for them in FileMaker Pro. As 
the school's student population is constantly changing, reports need to be written on individual children on a regular basis. The school also needed a good method of tracking children's involvement in special programs, and their database system does this for them. Although it is not currently linked to the CASES-21 network, in the future it could be.

The SERCT Centre visited offers a service to schools in the South Eastern Region assisting them develop their own databases. These are mainly designed to assist classroom teachers in writing parents' reports. None of the databases we viewed there, however, were used to track and monitor student academic progress or involvement in additional programs.

\section{CONCLUSION}

CASES-21 was designed to support school office administrative applications with reporting back to the Department of Education. It was not intended for use by classroom teachers. CASES-21 can be used relatively easily to export data to be used in other systems, however it cannot easily import data from other systems. This has led many schools to having two or more systems in operation, often containing similar data. The other problem with CASES-21 is that it is only available from the administrative network in schools (unconnected to the curriculum network accessible to classroom teachers), making it very difficult for teachers to access.

This study identified many features in CASES-21 that could benefit the classroom teacher but most are related to a teacher's administrative functions such as organising camps and excursions, sending letters to parents and so on. The problem of classroom teacher access to this system has meant that very few teachers can currently make use of this data. It is not that this is forbidden, just difficult. This study concentrated on how student data could be used to assist the classroom teacher to improve student learning, but did not identify any use of this data directly related to teaching. Most uses related instead to general teacher administrative tasks.

The investigation also found a number of other issues that would need to be considered before extensive use can be made of this data. Privacy was one important issue raised. CASES-21 and other systems in schools contain a lot of personal information on students and their families, and on teachers in schools. Most systems investigated in this study had high levels of security, but this is an issue that individual schools will clearly need to consider very carefully. Another issue was that of data storage. Developing systems to store and track student data over their time at school is a great idea, however after just a few years this will have built up to a very large amount of collected data. Some of this may be viewed regularly but other data not at all. Schools are required to keep all data on a student until this student has finished secondary school (Year 12). Data archiving is thus something schools will need to look into. 


\section{REFERENCES}

Davey, B. and Tatnall, A. (2003). Involving the Academic: A Test for Effective University ITEM Systems. Management of Education in the Information Age: The Role of ICT. Selwood, I., Fung A. C. W. and O'Mahony C. D. Assinippi Park, Massachusetts, Kluwer Academic Publishers / IFIP: 83-92.

Department of Education (2005). Information and Communications Technology: CASES21. Web page, Date accessed: October 2005, www.sofweb.vic.edu.au/ict/cases21

Eltham North Primary School (2003). Curriculum and Charter. Web, Date accessed: October 2005, http://www.elthamnorthps.vic.edu.au/c6.1_charter.htm

Tatnall, A. (1995). Information Technology and the Management of Victorian Schools Providing Flexibility or Enabling Better Central Control? Information Technology in Educational Management. Barta, B. Z., Telem M. and Gev Y. London, Chapman \& Hall: 99-108.

Tatnall, A. and Davey, B. (2001). Open ITEM Systems are Good ITEM Systems. Institutional Improvement through Information Technology in Educational Management. Nolan, P. Dordrecht, The Netherlands, Kluwer Academic Publishers: 59-69. 